\title{
ELECTRE I Method Using Hesitant Linguistic Term Sets: An Application to Supplier Selection
}

\author{
Ali Fahmi ${ }^{1}$, Cengiz Kahraman², Ümran Bilen ${ }^{3}$ \\ ${ }^{1}$ Istanbul Technical University, Department of Management Engineering, Macka, 34367 Istanbul, Turkey \\ E-mail:fahmi@itu.edu.tr \\ ${ }^{2}$ Istanbul Technical University, Department of Industrial Engineering, Macka, 34367 Istanbul, Turkey \\ E-mail:kahramanc@itu.edu.tr \\ ${ }^{3}$ Istanbul Technical University, Naval Architecture and Marine Engineering, Maslak, 34469 Istanbul, Turkey \\ E-mail: umranbilen@gmail.com
}

Received 7 September 2015

Accepted 18 December 2015

\begin{abstract}
Decision making is a common process in human activities. Every person or organization needs to make decisions besides dealing with uncertainty and vagueness associated with human cognition. The theory of fuzzy logic provides a mathematical base to model the uncertainities. Hesitant fuzzy linguistic term set (HFLTS) creates an appropriate method to deal with uncertainty in decision making. Managerial decision making generally implies that decision making process conducts multiple and conflicting criteria. Multi criteria decision analysis (MCDA) is a widely applied decision making method. Outranking methods are one type of MCDA methods which facilitate the decision making process through comparing binary relations in order to rank the alternatives. Elimination et Choix Traduisant la Réalité (ELECTRE), means elimination and choice that translates reality, is an outranking method. In this paper, an extended version of ELECTRE I method using HFLTS is proposed. Finally, a real case problem is provided to illustrate the HFLTS-ELECTRE I method.
\end{abstract}

Keywords: Multiple criteria decision analysis (MCDA), outranking methods, ELECTRE method, hesitant fuzzy linguistic terms set (HFLTS), ordered weighted averaging (OWA), computing with words (CWW)

\section{Introduction}

Multiple criteria decision analysis (MCDA) denotes to analyzing decision making situations that encounter with multiple and conflicting criteria. It refers to analyzing tools and systematic approaches that empower the decision maker (DM). They help DM to represent his/her preferences and consider all subjective and objective conditions to assess the decision elements $[1,2]$. MCDA methods provide a quantitative infrastructure to model the assessments of criteria and alternatives [3]. MCDA methods are classified into three major categories including multi-attribute value theory (MAVT), multi-objective mathematical programming, and outranking methods $[4,5,6,7,8,9]$.

(1) MAVT approach concerns hierarchical decision making problems with the overall goal on the top level and the criteria on the lowest level. MAVT involves in the weighting the criteria and assessment of alternatives with respect to criteria. Lastly, MAVT approach ranks the criteria through calculations of criteria weights and alternative assessments.

(2) Multi-objective mathematical programming methods focus on finding the aspiration points. These points can generate non-dominated solutions by scalarizing functions through reaching down from ideal solution $[10,11,12]$. 
(3) Outranking methods form two main steps: building the outranking relations, and exploiting the outranking relations [13]. At first, outranking methods systematically compare criteria. The binary comparisons construct the concordance and discordance sets which are linguistic comparisons. Then, these comparisons lead to numerical concordance and discordance indices.

There are different outranking methods including ELECTRE family, PROMETHEE family, QUALIFLES [14], ORESTE [15, 16], MELCHIOR [17], PRAGMA [18], MAPPACC [18], and TACTIC [19]. ELECTRE family includes ELECTRE I [20, 21], ELECTRE II [22, 23], ELECTRE III [24, 25], ELECTRE IV [26], ELECTRE IS [27], ELECTRE TRI [28], and ELECTRE $^{\text {GKMS }}$ [29]. PROMETHEE family contains PROMETHEE I [30], and PROMETHEE II [30].

The PROMETHEE family of outranking methods includes the PROMETHEE I for partial ranking of the alternatives and the PROMETHEE II for complete ranking of the alternatives, the PROMETHEE III for ranking based on interval, the PROMETHEE IV for complete or partial ranking of the alternatives when the set of viable solutions is continuous, the PROMETHEE $\mathrm{V}$ for problems with segmentation constraints, the PROMETHEE VI for the human brain representation [31].

ELECTRE family methods are the most widely used outranking approaches [29, 32]. ELECTRE I outranking method is the first ELECTRE method which was introduced by Benayoun, Roy, and Sussman [20] and Roy [21]. Decision makers use ELECTRE I to construct a partial prioritization and choose a set of promising alternatives [4]. ELECTRE II is used for ranking the alternatives based on the determination of concordance and discordance matrices for each criterion and alternative pair. In ELECTRE III, an outranking degree is established, representing an outranking creditability between two alternatives which makes this method more sophisticated. ELECTRE III is based on the principle of fuzzy logic and uses the preference and indifference thresholds while determining the concordance and discordance indices [13].

Outranking methods are extended to deal with imprecision and uncertainty of decision making process. Roy [33] and Siskos, Lochard, and Lombard [34] developed fuzzy outranking method. This method uses fuzzy concordance and discordance relation. Sevkli [35] applied fuzzy ELECTRE method for supplier selection.
Ertay and Kahraman [36] evaluated the design requirements by utilizing fuzzy outranking methods.

Afterwards, different extensions of fuzzy sets have been applied to outranking methods. Interval type-2 fuzzy sets have been employed in the ELECTRE method [37, 38]. Chen [39] implemented an ELECTRE based group decision making method using interval type-2 fuzzy sets. Devi and Yadav [40] developed an ELECTRE group decision making based on intuitionistic fuzzy sets for plant location selection. See Vahdani et al. [41], Li, Lin, and Chen [42], and Wue and Chen [43] developed ELECTRE method extension in an intuitionistic fuzzy environment. Hatami-Marbini and Tavana [4] applied fuzzy group decision making to extend ELECTRE I methodology. See Hatami-Marbini and Tavana [4] for more details.

Torra [44] proposed hesitant fuzzy sets (HFS) as a generalization of fuzzy sets. HFS are quite suitable in decision making when experts have to assess a set of alternatives. HFS were introduced to the literature for the common difficulty that often appears when the membership degree of an element must be established and the difficulty is not because of an error margin (as in intuitionistic fuzzy sets) or due to some possibility distribution (as in type-2 fuzzy sets), but rather because there are some possible values that cause hesitancy about which one would be the right one [45].

These new sets permit DM to represent his/her hesitation in decision making process. The mathematical background of hesitation is modeled by different membership functions. HFS establishes a relationship between the envelopes of fuzzy sets and generates new fuzzy sets with combined membership functions.

As decision making encounters linguistic information, we need to use computing with words (CWW) processes [46, 47, 48]. HFS provides an appropriate infrastructure to develop the concept of hesitant linguistic term set which is a useful CWW process. The experts involved in decision problems under uncertainty cannot easily provide a single term as an expression of his/her knowledge such as poor, good, very good, etc. because they might consider several terms at the same time or looking for a more complex linguistic term such as at least medium poor, at most very high, etc. Thus, Rodriguez, Martinez, and Herrara [49], and Liu and Rodriguez [50] proposed the hesitant fuzzy linguistic term set (HFLTS) and its application in decision making. This method could increase the ability and flexibility of linguistic elicitation of DM. HFLTS 
enables DM to represent the uncertainty in his/her assessments of actions, criteria, alternatives, etc. [49]. This would be implemented by context-free grammars based on the fuzzy linguistic tools to compare the expressions.

In this study, the ELECTRE I method is extended based on HFLTS. This new approach could be applied to decision making problems and deal with the uncertainty and imprecision of multiple criteria decision making. This method contains two phases: HFLTS phase and ELECTRE I phase. Firstly, HFLTS method considers DM's hesitation between several values to evaluate the decision elements and manage the uncertainty of decision making. These hesitant linguistic terms are expressed by numerical fuzzy values. Next, in ELECTRE phase, we apply ELECTRE I method to analyze the decision making. This would be accomplished through building the outranking relations, and then exploiting the outranking relations. Finally, we can rank the alternatives and make an appropriate decision.

It is worthy to mention that ELECTRE method has an important pitfall [4]. DM must initiate this method by precise measurement of the performance ratings and the weights of criteria [5]. On the other hand, DM may prefer to express his/her judgment by linguistic expressions [51, 52, 53]. This approach takes this weakness into account and modifies it by utilizing linguistic expressions in decision making process and allows DM to evaluate the real world problem with imprecise and vague ratings.

This paper is organized as follows: Section 2 includes needed definitions and arithmetic operations about HFLTS and ELECTRE I method. In Section 3, the step-by-step methodology of hesitant fuzzy linguistic term set ELECTRE I (HFLTS-ELECTRE I) is proposed. Next, a real case study is added in Section 4. Lastly, the conclusions and future works are presented in Section 5.

\section{Preliminaries}

In this section, the basic definitions and arithmetic operations are given.

\subsection{Comparative Linguistic Expressions}

In many decision making situations, DM deals with uncertain and imprecise information to express his/her judgment. Zadeh [54] presented fuzzy sets and then developed the concept of linguistic variables [51]. Based on these concepts, Rodriguez, Martinez, and Herrera [49] developed the concepts of fuzzy hesitant linguistic terms set (HFLTS).

Definition 1. [51] A linguistic variable has five characteristics and is defined as $(H, T(H), U, G, M)$, where $H$ is the name of variable, $T(H)$ is the term set of $H$, i.e., the collection of its linguistic values, $U$ is the universe of discourse, $G$ is a syntactic rule which generates the terms in $T(H)$, and $M$ is a semantic rule which associates with each linguistic value $\mathrm{X}$ its meaning, $\mathrm{M}(\mathrm{X})$ denotes a fuzzy subset of $\mathrm{U}$.

Most of decision making situations deal with comparative judgments. DM provides relative assessments by comparing the alternatives. Therefore, in order to apply the concept of HFLTS in decision making problems, we should elicit the comparative linguistic expressions [55].

Definition 2. [49, 50] A hesitant fuzzy linguistic term set (HFLTS) is shown by $H_{S}$, and is an ordered finite subset of the consecutive linguistic terms set $S=$ $\left\{S_{0}, S_{1}, \ldots, S_{g}\right\}$.

Definition 3. The envelope of an HFLTS is a linguistic interval that its upper bound and lower bound determine the limits of the envelope as follows:

$$
\begin{aligned}
& \operatorname{env}\left(H_{S}\right)=\left[H_{S^{-}}, H_{S^{+}}\right], H_{S^{-}} \leq H_{S^{+}} \\
& H_{S^{+}}=\max \left\{S_{i}\right\} \quad \forall S_{i} \in H_{S} \\
& H_{S^{-}}=\min \left\{S_{i}\right\} \quad \forall S_{i} \in H_{S}
\end{aligned}
$$

As mentioned above, DM applies comparative linguistic expressions to assess the criteria and alternatives of a common decision making problem. It is appropriate to represent the comparative expressions by fuzzy membership functions [50]. Thus, trapezoidal membership function is used and ordered weighted averaging (OWA) operator is established [56] in order to compute the elements of fuzzy membership function. OWA weights would represent the decision maker's hesitation in linguistic terms. There are different 
approaches to obtain the OWA weights, but in this study Filev and Yager's [56] approach is applied.

Definition 4. Let OWA operator maps from dimension $n$ as follows:

$O W A: R^{n} \rightarrow R$

$O W A\left(a_{1}, a_{2}, \ldots, a_{n}\right)=\sum_{j=1}^{n} w_{j} b_{j}$

where $a_{1}, a_{2}, \ldots, a_{n}$ is the aggregated set of arguments and $b_{j}$ is the $j$ th largest argument of the aggregated set, and the associated weighting vector $W=\left(w_{1}, w_{2}, \ldots, w_{n}\right)^{T}$ satisfies $\quad w_{i} \in[0,1] \quad \forall i=$ $1,2, \ldots, n$

$\sum_{i=1}^{n} w_{i}=1$

In order to calculate the parameters $b$ and $c$, OWA operator is implemented as follows:

$b=O W A_{W^{s}}\left(a_{M}^{i}, a_{M}^{i+1}, \ldots, a_{M}^{j}\right)$

$c=O W A_{W} t\left(a_{M}^{i}, a_{M}^{i+1}, \ldots, a_{M}^{j}\right)$

where $W^{s}$ and $W^{t}$ represent the form of OWA weighting vectors for computing $b$ and $c$, respectively. $s, t=1,2$ and $s \neq t$ or $s=t$.

Definition 5. Let $\alpha$ be the parameter in the unit interval $(0,1)$. This parameter is used to calculate the first type of weights of OWA operator as follows:

$$
\begin{aligned}
& W^{1}=\left(w_{1}^{1}, w_{2}^{1}, \ldots, w_{n}^{1}\right)^{T} \\
& w_{1}^{1}=\alpha, w_{2}^{1}=\alpha(1-\alpha), w_{3}^{1}=\alpha(1-\alpha)^{2}, \ldots, w_{n-1}^{1}= \\
& \quad \alpha(1-\alpha)^{n-2}, \\
& w_{n}^{1}=(1-\alpha)^{n-1}
\end{aligned}
$$

Also, the second type of weights of OWA operator is as follows:

$$
\begin{gathered}
W^{2}=\left(w_{1}^{2}, w_{2}^{2}, \ldots, w_{n}^{2}\right)^{T} \\
w_{1}^{2}=\alpha, w_{2}^{2}=\alpha(1-\alpha), w_{3}^{2}=\alpha(1-\alpha)^{2}, \ldots, w_{n-1}^{2}= \\
\alpha(1-\alpha)^{n-2}, \\
w_{n}^{2}=(1-\alpha)^{n-1}
\end{gathered}
$$

\subsection{Fuzzy arithmetic operations}

Based on the previous definitions, proposed method employs trapezoidal fuzzy numbers and arithmetic operations of trapezoidal fuzzy numbers should be calculated. The required concepts are defined below.

Definition 6. A fuzzy number $\tilde{A}=(a, b, c, d)$ is a trapezoidal fuzzy number shown in Fig. 1 , and its membership function is given by:

$$
\mu(x)=\left\{\begin{array}{cc}
0, & x<a, \\
\frac{x-a}{b-a}, & a \leq x \leq b, \\
1, & b<x<c, \\
\frac{d-x}{d-c}, & c \leq x \leq d, \\
0, & x>d,
\end{array}\right.
$$

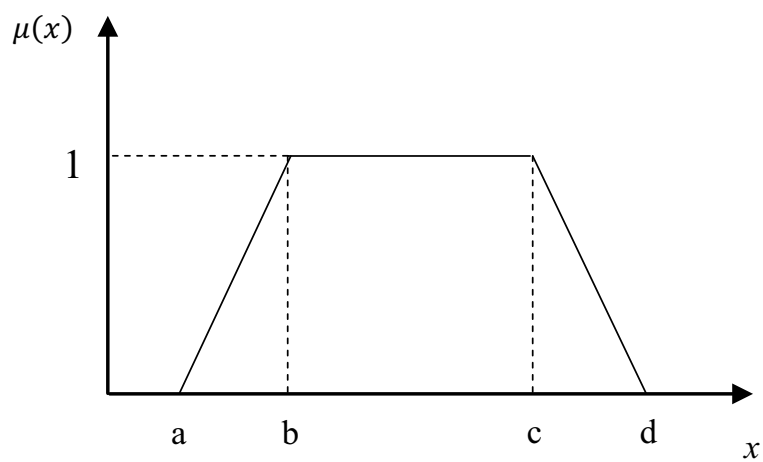

Fig. 1. Trapezoidal fuzzy number, $\widetilde{A}=(\boldsymbol{a}, \boldsymbol{b}, \boldsymbol{c}, \boldsymbol{d})$

Definition 7. Let $\mathrm{A}$ and $\mathrm{B}$ be two positive trapezoidal fuzzy numbers, where $\tilde{A}=(a, b, c, d)$ and $\tilde{B}=(p, q, r, s)$. The arithmetic operations between $\tilde{A}$ and $\tilde{B}$ is as follows:

Addition operation:

$\tilde{A} \oplus \tilde{B}=(a+p, b+q, c+r, d+s)$

Subtraction operation:

$\tilde{A} \ominus \widetilde{B}=(a-s, b-r, c-q, d-p)$

Multiplication operation:

$\tilde{A} \otimes \tilde{B} \cong(a p, b q, c r, d s)$

Division operation:

$\tilde{A} \oslash \tilde{B} \cong\left(\frac{a}{s}, \frac{b}{r}, \frac{c}{q}, \frac{d}{p}\right)$

Multiplication operation:

$u . \tilde{A}=\tilde{A} . u= \begin{cases}(u \cdot a, u \cdot b, u \cdot c, u \cdot d) & \text { if } u \geq 0 \\ (u \cdot d, u \cdot c, u \cdot b, u \cdot a) & \text { if } u<0\end{cases}$

Division operation:

$\frac{\tilde{A}}{u}= \begin{cases}\left(\frac{a}{u}, \frac{b}{u}, \frac{c}{u}, \frac{d}{u}\right) & \text { if } u \geq 0 \\ \left(\frac{d}{u}, \frac{c}{u}, \frac{b}{u}, \frac{a}{u}\right) & \text { if } u \leq 0\end{cases}$

\subsection{Basic definitions of ELECTRE I}

As mentioned earlier, ELECTRE I is an outranking method that is characterized due to analyzing binary relations of the alternatives. Some definitions regarding outranking relations are provided as follows $[4,5,57$, 58, 59]:

Definition 8. In ELECTRE I method, DM indicates the preferences by binary outranking relations. Let $x$ and $y$ be two alternatives. " $x S y$ " means " $x$ is at least as good as $y^{\prime \prime}$. 
Definition 9. The concept of outranking relation is based on two concepts including the concordance and the discordance. The statement of " $x S y$ " provides insights into these concepts: The concordance concept: For an outranking " $x S y$ ” to be validated, a sufficient majority of the criteria should be in favor of this assertion. On the other hand, when the concordance condition holds, discordance concept implies that none of the criteria in the minority should oppose too strongly to the assertion " $x S y$ ".

\section{Methodology}

As mentioned above, we propose a new fuzzy ELECTRE I method based on HFLTS. This method facilitates decision making process due to utilizing linguistic terms and context-free grammars for evaluating the importance weights of the criteria and performance ratings. Since DMs compare the criteria and alternatives to present relative assessments, comparative linguistic expressions are needed for the assessments of alternatives and criteria. Therefore, HFLTS method contributes to determine fuzzy numbers for hesitant judgments. Then, fuzzy ELECTRE I outranking method is established to complete the decision making process. Our methodology includes two main phases: HFLTS operations and the application of fuzzy ELECTRE I outranking method.

\section{First phase: HFLTS operations}

Step 1. Determine the semantics and syntax of linguistic terms set and context-free grammar $G_{H}$.

In this phase, DM should determine the decision making conditions to apply CWW process. The first step is to determine the semantic and syntax of comparative linguistic terms set. Definition 1 also lets us to determine the context-free grammar $G_{H}$. An example of context-free grammar is provided below [50]:

$G_{H}=\left\{V_{N}, V_{T}, I, P\right\}$

where $V_{N}$ shows non-terminal symbols and $V_{T}$ shows terminal symbols as follows:

$$
\begin{aligned}
& V_{N}=\left\{\begin{array}{c}
\langle\text { primary term }\rangle,\langle\text { binary relation }\rangle, \\
\langle\text { unary term }\rangle,\langle\text { conjunction }\rangle
\end{array}\right\} \\
& V_{T}=\left\{\text { at least, at most, between, and }, S_{0}, S_{1}, \ldots, S_{g}\right\} \\
& I \in V_{N}
\end{aligned}
$$

$P$ indicates the production rules for the context-free grammar $G_{H}$. Bracket signs shows optimal elements and the symbol "|" indicates alternative elements. In this example, the production rules are as follows:

$$
P=\left\{\begin{array}{c}
\text { primary term }::=s_{0}\left|s_{1}\right| \ldots \mid s_{g}, \\
\langle\text { binary relation }\rangle::=\text { between } \\
\langle\text { unary relation }\rangle::=\text { at least } \mid \text { at most } \mid \text { lower than } \mid \text { greater than }, \\
\langle\text { conjunction }\rangle::=\text { and }
\end{array}\right\}
$$

This set specifies the fuzzy partition of the HFLTS phase. This partitioning lets us to represent the fuzzy envelopes of the assessments. Three values are considered including left value (L), middle value (M), and right value $(\mathrm{R})$ for the partitioning. As you see in Fig. 2, each triangular represents three values L, M, and R. In the proposed approach, assessments are represented by trapezoidal fuzzy numbers.

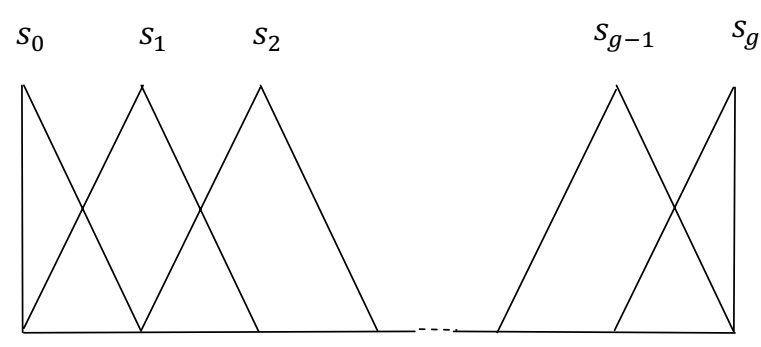

Fig. 2. Fuzzy partitioning.

Step 2. Gather the assessments of performance and criteria.

In this step, DM evaluates the performance ratings with respect to criteria in square matrices. Also, the weights of criteria are calculated by DM's assessments of criteria with respect to goal.

Step 3. Transform the assessments into HFLTS by transformation function $E_{G_{H}}$.

Let $S=\left\{s_{0}, s_{1}, \ldots, s_{g}\right\}$ be the linguistic terms set. DM evaluates the performance and criteria by comparative linguistic terms based on the defined context-free grammar $G_{H}$. The transformation of the evaluations into HFLTS will be carried out by transformation function $E_{G_{H}}$ as follows:

$$
\begin{aligned}
& E_{G_{H}}\left(s_{i}\right)=\left\{s_{i} \mid s_{i} \in S\right\}=\left\{s_{i}\right\}, \\
& E_{G_{H}}\left(\text { between } s_{i} \text { and } s_{j}\right)=\left\{s_{k} \mid s_{i} \leq s_{k} \leq s_{j} \text { and } s_{k} \in\right. \\
& S\}=\left\{s_{i}, s_{i+1}, \ldots, s_{j}\right\}, \\
& E_{G_{H}}\left(\text { at least } s_{i}\right)=\left\{s_{j} \mid s_{j} \geq s_{i} \text { and } s_{j} \in S\right\}= \\
& \left\{s_{i}, s_{i+1}, \ldots, s_{g}\right\}, \\
& \qquad E_{G_{H}}\left(\text { at most } s_{i}\right)=\left\{s_{j} \mid s_{j} \leq s_{i} \text { and } s_{j} \in S\right\} \\
& =\left\{s_{0}, s_{1}, \ldots, s_{i}\right\}
\end{aligned}
$$


Step 4 : Obtain an aggregate set for each assessment.

In this step, the fuzzy envelope is obtained through calculating the elements of a trapezoidal fuzzy number. We calculate these elements by aggregate set as follows: Let $A$ be the aggregate set for $E_{G_{H}}$ (between $s_{i}$ and $s_{j}$ ).

$$
\begin{aligned}
& A_{\text {between }}= \\
& \left\{a_{L}^{i}, a_{M}^{i}, a_{L}^{i+1}, a_{R}^{i}, a_{M}^{i+1}, a_{L}^{i+2}, a_{R}^{i+1}, \ldots, a_{L}^{j}, a_{R}^{j-1}, a_{M}^{j}, a_{R}^{j}\right\}
\end{aligned}
$$

$A_{\text {at least }}=$

$\left\{a_{L}^{i}, a_{M}^{i}, a_{L}^{i+1}, a_{R}^{i}, a_{M}^{i+1}, a_{L}^{i+2}, a_{R}^{i+1}, \ldots, a_{L}^{g}, a_{R}^{g-1}, a_{M}^{g}, a_{R}^{g}\right\}$

$A_{\text {at most }}=$

$\left\{a_{L}^{0}, a_{M}^{0}, a_{L}^{1}, a_{R}^{0}, a_{M}^{1}, a_{L}^{2}, a_{R}^{1}, \ldots, a_{L}^{i}, a_{R}^{i-1}, a_{M}^{i}, a_{R}^{i}\right\}$

As you see in Fig. 2, $a_{L}^{k+1}=a_{M}^{k}=a_{R}^{k-1}$ for $k=$ $1,2, \ldots, g-1$. So that, the Eqs. (15), (16), and (17) are simplified as follows:

$$
\begin{aligned}
& A_{\text {between }}=\left\{a_{L}^{i}, a_{M}^{i}, a_{M}^{i+1}, \ldots, a_{M}^{j}, a_{R}^{j}\right\} \\
& A_{\text {at least }}=\left\{a_{L}^{i}, a_{M}^{i}, a_{M}^{i+1}, \ldots, a_{M}^{g}, a_{R}^{g}\right\} \\
& A_{\text {at most }}=\left\{a_{L}^{0}, a_{M}^{0}, a_{M}^{1}, \ldots, a_{M}^{i}, a_{R}^{i}\right\}
\end{aligned}
$$

Step 5. Obtain fuzzy envelope for each assessment.

$$
\begin{aligned}
& \tilde{T}_{\text {between }}=(a, b, c, d), \\
& a=\min A_{\text {between }}=\min \left\{a_{L}^{i}, a_{M}^{i}, a_{M}^{i+1}, \ldots, a_{M}^{j}, a_{R}^{j}\right\}= \\
& a_{L}^{i}, \\
& d=\max A_{\text {between }}=\max \left\{a_{L}^{i}, a_{M}^{i}, a_{M}^{i+1}, \ldots, a_{M}^{j}, a_{R}^{j}\right\}= \\
& a_{R}^{j}, \\
& b=O W A_{W^{2}}\left(a_{M}^{i}, a_{M}^{i+1}, \ldots, a_{M}^{j}\right), \\
& c=O W A_{W^{1}}\left(a_{M}^{i}, a_{M}^{i+1}, \ldots, a_{M}^{j}\right) .
\end{aligned}
$$

As in Definition 5, we can compute the weights of OWA operator to calculate element $b$, and $c$ for "between" comparative linguistic terms set. The first type of weights of OWA operator is used to calculate $b$ and the second type of weights of OWA operator to calculate $c$ as follows:

I) If $i+j$ is odd, then

$$
\begin{aligned}
& b=O W A_{W^{2}}\left(a_{M}^{i}, a_{M}^{i+1}, \ldots, a_{M}^{\frac{i+j-1}{2}}\right), \\
& c=O W A_{W^{1}}\left(a_{M}^{j}, a_{M}^{j-1}, \ldots, a_{M}^{\frac{i+j+1}{2}}\right), \\
& W^{2}=\left(w_{1}^{2}, w_{2}^{2}, \ldots, w_{j-i+1 / 2}^{2}\right)^{T} \text { and } \alpha_{1}=\frac{g-(j-i)}{g-1}
\end{aligned}
$$

$$
\begin{aligned}
& \text { where } w_{1}^{2}=\alpha_{1}^{\frac{j-i-1}{2}}, w_{2}^{2} \\
& =\left(1-\alpha_{1}\right) \alpha_{1} \frac{j-i-3}{2}, \ldots, w_{\frac{j-i-1}{2}}^{2} \\
& =\left(1-\alpha_{1}\right) \alpha_{1}, w_{\frac{j-i+1}{2}}^{2}=\left(1-\alpha_{1}\right)
\end{aligned}
$$

$b=w_{1}^{2} \cdot a_{M}^{\frac{i+j-1}{2}}, w_{2}^{2} \cdot a_{M}^{\frac{i+j-3}{2}}, \ldots, w_{\frac{j-i-1}{2}}^{2} \cdot a_{M}^{i+1}, w_{\frac{j-i+1}{2}}^{2} \cdot a_{M}^{i}$ and $W^{1}=\left(w_{1}^{1}, w_{2}^{1}, \ldots, w_{j-i+1 / 2}^{1}\right)^{T}$ and $\alpha_{2}=1-\alpha_{1}=$ $\frac{(j-i)-1}{g-1}$

where $w_{1}^{1}=\alpha_{2}, w_{2}^{1}=\alpha_{2}\left(1-\alpha_{2}\right), \ldots, w_{\frac{j-i-1}{2}}^{2}$

$$
\begin{gathered}
=\alpha_{2}\left(1-\alpha_{2}\right)^{\frac{j-i-3}{2}}, w_{\frac{j-i+1}{2}}^{2}=\left(1-\alpha_{2}\right)^{\frac{j-i-1}{2}} \\
c=w_{1}^{1} \cdot a_{M}^{\frac{i+j+1}{2}}, w_{2}^{1} \cdot a_{M}^{\frac{i+j-1}{2}}, \ldots, w_{\frac{j-i-1}{2}}^{1} \cdot a_{M}^{i+1}, w_{\frac{j-i+1}{2}}^{1} \cdot a_{M}^{i}
\end{gathered}
$$

II) If $i+j$ is even, then

$$
\begin{aligned}
& b=O W A_{W^{2}}\left(a_{M}^{i}, a_{M}^{i+1}, \ldots, a_{M}^{\frac{i+j}{2}}\right) \\
& c=O W A_{W^{1}}\left(a_{M}^{j}, a_{M}^{j-1}, \ldots, a_{M}^{\frac{i+j}{2}}\right) \\
& W^{2}=\left(w_{1}^{2}, w_{2}^{2}, \ldots, w_{j-i+2 / 2}^{2}\right)^{T} \\
& \text { where } w_{1}^{2}=\alpha_{1}^{\frac{j-i}{2}}, w_{2}^{2}=\left(1-\alpha_{1}\right) \alpha_{1}^{\frac{j-i-2}{2}}, \ldots, w_{\frac{j-i}{2}}^{2} \\
& b=w_{1}^{2} \cdot a_{M}^{\frac{i+j}{2}}, w_{2}^{2} \cdot a_{M}^{\frac{i+j-2}{2}}, \ldots, w_{\frac{j-i}{2}}^{2} \cdot a_{M}^{i+1}, w_{\frac{j-i+2}{2}}^{2} \cdot a_{M}^{i} \\
& \text { and } W^{1}=\left(w_{1}^{1}, w_{2}^{1}, \ldots, w_{j-i+2 / 2}^{1}\right)^{T} \\
& \text { where } w_{1}^{1}=\alpha_{2}, w_{2}^{1}=\alpha_{2}\left(1-\alpha_{2}\right), \ldots, w_{\frac{j-i}{2}}^{\frac{1}{2}} \\
& =\alpha_{2}\left(1-\alpha_{2}\right)^{\frac{j-i-2}{2}}, w_{\frac{j-i+2}{2}}^{1}=\left(1-\alpha_{2}\right)^{\frac{j-i}{2}} \\
& \quad c=w_{1}^{1} \cdot a_{M}^{\frac{i+j}{2}}, w_{2}^{1} \cdot a_{M}^{\frac{i+j-2}{2}}, \ldots, w_{\frac{j-i}{2}}^{1} \cdot a_{M}^{j-1}, w_{\frac{j-i+2}{2}}^{1} a_{M}^{j}
\end{aligned}
$$

Finally, the HFLTS envelope will be formed as $\widetilde{T}_{\text {between }}=\left(a_{L}^{i}, b, c, a_{R}^{j}\right)$. See Fig. 3.

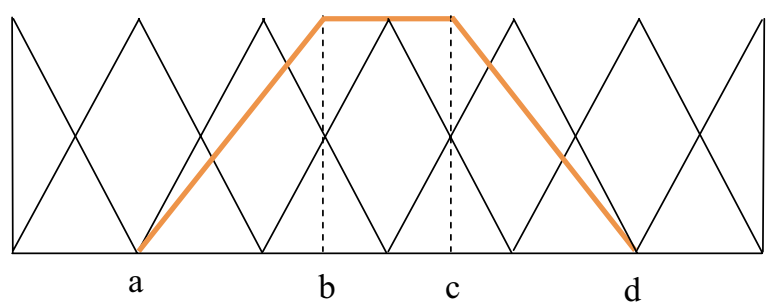

Fig. 3. Fuzzy Envelope for comparative linguistic expression "between" 
$\tilde{T}_{\text {at least }}=(a, b, c, d)$,

$a=\min A_{\text {at least }}=\min \left\{a_{L}^{i}, a_{M}^{i}, a_{M}^{i+1}, \ldots, a_{M}^{g}, a_{R}^{g}\right\}=a_{L}^{i}$,

$d=\max A_{\text {at least }}=\max \left\{a_{L}^{i}, a_{M}^{i}, a_{M}^{i+1}, \ldots, a_{M}^{g}, a_{R}^{g}\right\}=a_{R}^{g}$

$b=O W A_{W^{2}}\left(a_{M}^{i}, a_{M}^{i+1}, \ldots, a_{M}^{g}\right)$

$c=O W A_{W^{2}}\left(a_{M}^{i}, a_{M}^{i+1}, \ldots, a_{M}^{g}\right)$

As can be seen in Definition 5, the weights of OWA operator to compute element $b$ for "at least" comparative linguistic terms set are as follows:

$n=g-i+1$,

$W^{2}=\left(w_{1}^{2}, w_{2}^{2}, \ldots, w_{n}^{2}\right)^{T}$ and $\alpha=i / g$

where $\quad w_{1}^{2}=\alpha^{g-i}, w_{2}^{2}=(1-\alpha) \alpha^{g-i-1}, \ldots, w_{g-i}^{2}=$ $\alpha(1-\alpha)$

$w_{g-i+1}^{2}=1-\alpha$

$b=w_{1}^{2} \cdot a_{M}^{g}, w_{2}^{2} \cdot a_{M}^{g-1}, \ldots, w_{g-i}^{2} \cdot a_{M}^{i+1}, w_{g-i+1}^{2} \cdot a_{M}^{i}$,

$b=\alpha^{g-i} \cdot a_{M}^{g},(1-\alpha) \alpha^{g-i-1} \cdot a_{M}^{g-1}, \ldots$,

$c=a_{M}^{g}$

$$
\alpha(1-\alpha) \cdot a_{M}^{i+1},(1-\alpha) \cdot a_{M}^{i}
$$

Finally, the HFLTS envelope is formed as $\widetilde{T}_{\text {at least }}=$ $\left(a_{L}^{i}, b, a_{M}^{g}, a_{L}^{g}\right)$. See Fig. 4.

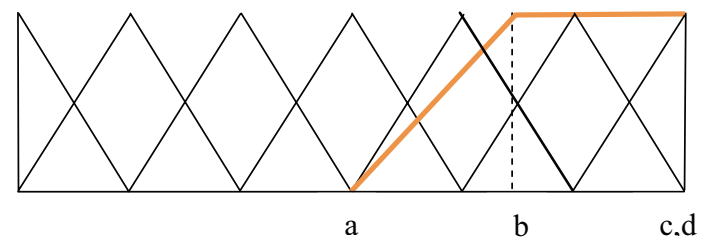

Fig. 4. Fuzzy Envelope for comparative linguistic expression "at least".

$\tilde{T}_{a t \text { most }}=(a, b, c, d)$,

$a=\min A_{\text {at most }}=\min \left\{a_{L}^{0}, a_{M}^{0}, a_{M}^{1}, \ldots, a_{M}^{j}, a_{R}^{j}\right\}=a_{L}^{0}$,

$d=\max A_{\text {at most }}=\max \left\{a_{L}^{0}, a_{M}^{0}, a_{M}^{1}, \ldots, a_{M}^{j}, a_{R}^{j}\right\}=a_{R}^{j}$

$b=O W A_{W^{1}}\left(a_{M}^{0}, a_{M}^{1}, \ldots, a_{M}^{j}\right)$

$c=O W A_{W^{1}}\left(a_{M}^{0}, a_{M}^{1}, \ldots, a_{M}^{j}\right)$

As you see in Definition 5, the weights of OWA operator to compute element $c$ for "at most" comparative linguistic terms set are as follows:

$n=i+1$,

$W^{1}=\left(w_{1}^{2}, w_{2}^{2}, \ldots, w_{n}^{2}\right)^{T}$ and $\alpha=i / g$

where $\quad w_{1}^{1}=\alpha, w_{2}^{1}=\alpha(1-\alpha), \ldots, w_{i}^{1}=\alpha(1-$

$\alpha)^{i-1}, w_{i+1}^{1}=(1-\alpha)^{i}$

$c=w_{1}^{1} \cdot a_{M}^{i}, w_{2}^{1} \cdot a_{M}^{i-1}, \ldots, w_{i}^{1} \cdot a_{M}^{1}, w_{i+1}^{1} \cdot a_{M}^{0}$,

$c=\alpha \cdot a_{M}^{i}, \alpha(1-\alpha) \cdot a_{M}^{i-1}, \ldots, \alpha(1-\alpha)^{i-1} \cdot a_{M}^{1},(1-\alpha)^{i} \cdot a_{M}^{0}$

$b=a_{M}^{0}$
Finally, the HFLTS envelope is formed as $\widetilde{T}_{a t \text { most }}=$ $\left(a_{L}^{0}, a_{M}^{0}, c, a_{R}^{i}\right)$. See Fig. 5 .

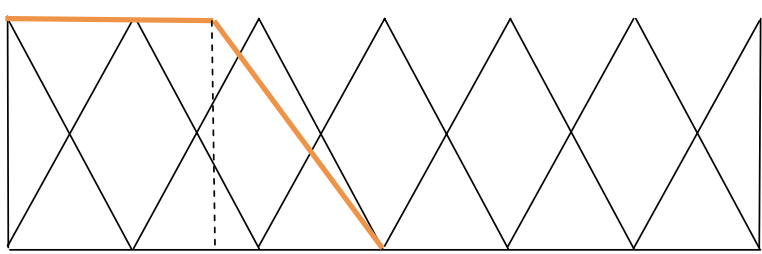

$\mathrm{a}, \mathrm{b}$

c

d

Fig. 5. Fuzzy Envelope for comparative linguistic expression "at most"

\section{Second phase: ELECTRE I outranking method}

Step 6. Defuzzify and rank the alternatives for each criterion.

In this step, the trapezoidal fuzzy values, which DM evaluated the alternatives in previous steps, will be defuzzified. The center of gravity defuzzification method is applied to rank alternatives with respect to each criterion.

Then, the utility matrix $\widetilde{U}$ is built. By taking utility matrix into account, assessment matrices will be formed to compare alternatives with respect to each criterion. The trapezoidal fuzzy elements of final utility matrix form the performance ratings as in Eq. (18).

$\widetilde{U}=\left[\begin{array}{cccc}- & \tilde{t}_{12} & \ldots & \tilde{t}_{1 n} \\ \tilde{t}_{21} & - & \ldots & \tilde{t}_{2 n} \\ \vdots & \vdots & \ddots & \vdots \\ \tilde{t}_{m 1} & \tilde{t}_{m 2} & \cdots & -\end{array}\right]$

The decision matrix $\tilde{I}$ is also built to compare the importance of criteria. Next, the weight of each criterion could be obtained through computing the average of the elements in each row using summation and division rules of trapezoidal fuzzy numbers. See Definition 7 for more details. Finally, the weight matrix will be obtained as Eq. (20).

$$
\begin{gathered}
\tilde{I}=\left[\begin{array}{cccc}
- & \tilde{F}_{12} & \ldots & \tilde{F}_{1 n} \\
\tilde{F}_{21} & - & \ldots & \tilde{F}_{2 n} \\
\vdots & \vdots & \ddots & \vdots \\
\tilde{F}_{m 1} & \tilde{F}_{m 2} & \ldots & -
\end{array}\right] \\
\tilde{W}=\left[\tilde{W}_{1}, \tilde{W}_{2}, \ldots, \tilde{W}_{m}\right]^{T}
\end{gathered}
$$


where $\quad \widetilde{W}_{1}=\frac{\sum_{j=2}^{n} F_{1 j}}{n}, \quad \tilde{W}_{2}=\frac{\sum_{j=\mathrm{z}}^{n} F_{z j}}{n}, \quad$ and $\widetilde{W}_{m}=\frac{\sum_{j=2}^{n} \vec{F}_{m j}}{n}$

Since the values in the matrices are between 0 and 1 , there is no need to obtain a normalized matrix. The weight matrix $\widetilde{W}$ and the utility matrix $\widetilde{U}$ are multiplied to construct weighted utility matrix $\tilde{V}$ as follows:

$\tilde{V}=\left[\begin{array}{cccc}\tilde{v}_{11} & \tilde{v}_{12} & \cdots & \tilde{v}_{1 n} \\ \tilde{v}_{21} & \tilde{v}_{22} & \cdots & \tilde{v}_{2 n} \\ \vdots & \vdots & \cdots & \vdots \\ \tilde{v}_{m 1} & \tilde{v}_{m 2} & \cdots & \tilde{v}_{m n}\end{array}\right]$

where

$\tilde{v}_{i j}=\left(v_{i j}^{l}, v_{i j}^{p}, v_{i j}^{q}, v_{i j}^{u}\right)=\left(w_{j}^{l} t_{i j}^{l}, w_{j}^{p} t_{i j}^{p}, w_{j}^{q} t_{i j}^{q}, w_{j}^{u} t_{i j}^{u}\right)$, $i=1,2, \ldots, m$, and $j=1,2, \ldots, n$.

Step 7. Calculate the fuzzy concordance indices and discordance indices.

The fuzzy concordance matrix is built as Eq. (21). The elements of this matrix are measured by pairwise comparison of alternatives. In this regard, two alternatives $a_{f}$ and $a_{g}$ are considered. Using Definition 8 , the outranking relation $a_{g} S a_{g f}$ will be defined. The arguments in favor of this statement " $a_{f}$ outranks $a_{g}$ " is measured to obtain the fuzzy concordance indices as follows:

$\tilde{C}=\left[\begin{array}{cccccc}- & \ldots & \tilde{c}_{g 1} & \ldots & \tilde{c}_{1(m-1)} & \tilde{c}_{1 m} \\ \vdots & \ddots & \vdots & \ddots & \vdots & \vdots \\ \tilde{c}_{g 1} & \ldots & \tilde{c}_{g f} & \ldots & \tilde{c}_{g(m-1)} & \tilde{c}_{g m} \\ \vdots & \ddots & \vdots & \ddots & \vdots & \vdots \\ \tilde{c}_{m 1} & \ldots & \tilde{c}_{m f} & \ldots & \tilde{c}_{m(m-1)} & -\end{array}\right]$

$\tilde{c}_{g f}=\left(c_{g f}^{l}, c_{g f}^{p}, c_{g f}^{q}, c_{g f}^{u}\right)$

where $\quad c_{g f}^{l}=\frac{\Sigma_{k: x_{i k}} \geq x_{j k} w_{k}^{l}}{W}, \quad c_{g f}^{p}=\frac{\Sigma_{k: x_{i k} \geq x_{j k} w_{k}^{p}}}{W}$,

$c_{g f}^{q}=\frac{\sum_{k: x_{i k}} \geq_{j k} w_{k}^{q}}{W}$, and $c_{g f}^{u}=\frac{\sum_{k: x_{i k} \geq x_{j k}} w_{k}^{u}}{W}$

and $W=\sum_{i=1}^{m} \tilde{w}_{i}$.

In addition, the discordance set is formed to construct the discordance matrix. The concept of discordance set is in contrast to the concept of concordance set. If DM has doubt upon the statement " $a_{f}$ outranks $a_{g}$ " and DM is against the assertion " $a_{g}$ is at least as good as $a_{f}$ ", we can represent the discordance matrix and the arguments as follows [60]:

$D=\left[\begin{array}{cccccc}- & \ldots & d_{g 1} & \ldots & d_{1(m-1)} & d_{1 m} \\ \vdots & \ddots & \vdots & \ddots & \vdots & \vdots \\ d_{g 1} & \ldots & d_{g f} & \ldots & d_{g(m-1)} & d_{g m} \\ \vdots & \ddots & \vdots & \ddots & \vdots & \vdots \\ d_{m 1} & \ldots & d_{m f} & \ldots & d_{m(m-1)} & -\end{array}\right]$ (22)

where $\quad d_{g f}=\frac{\sum_{h}{ }^{a} \tilde{v}_{g h}-\tilde{v}_{f h} \mid}{\sum_{h}\left|\tilde{v}_{g h}-\tilde{v}_{f h}\right|}, \quad$ if $\quad \tilde{v}_{g h}<\tilde{v}_{f h}$,

$g=1,2, \ldots, m$, and $f=1,2, \ldots, n$, and

$\left|\tilde{v}_{g h}-\tilde{v}_{f h}\right|=\left|\left(v_{g h}^{l}-v_{f h}^{u}, v_{g h}^{p}-v_{f h}^{q}, v_{g h}^{q}-v_{f h}^{p}, v_{g h}^{u}-v_{f h}^{l}\right)\right|$.

The discordance indices are obtained between alternatives $i$ and $j$ with respect to the criterion $h^{\circ} . \tilde{v}_{i h}$ and $\tilde{v}_{j h}$ are ranked by Yager's centroid index [61]. Then, the defuzzification method, center of gravity will be employed to calculate the discordance index.

Since this method calculates the outranking relations without defining concordance and discordance thresholds, a combination method to unite fuzzy concordance and discordance matrices is proposed. A modified version of Aouam and Chang's [62] formula is applied to calculate the elements of matrix $D^{\prime}$. Hence, $D^{\prime}$ is formed by subtracting each element of the discordance matrix from 1 . Then, the fuzzy global matrix $\widetilde{Z}$ will be calculated through peer to peer multiplication of the elements of the matrices $\tilde{C}$ and $D^{\prime}$ (using Eq. (11)) as follows:

$$
\tilde{Z}=\tilde{C} \otimes D^{\prime}
$$

where

$$
D^{\prime}=\left[\begin{array}{cccccc}
- & \ldots & 1-d_{g 1} & \ldots & 1-d_{1(m-1)} & 1-d_{1 m} \\
\vdots & \ddots & \vdots & \ddots & \vdots & \vdots \\
1-d_{g 1} & \ldots & 1-d_{g f} & \ldots & 1-d_{g(m-1)} & 1-d_{g m} \\
\vdots & \ddots & \vdots & \ddots & \vdots & \vdots \\
1-d_{m 1} & \ldots & 1-d_{m f} & \ldots & 1-d_{m(m-1)} & -
\end{array}\right]
$$

Step 8. Compare the alternatives by fuzzy Kernel diagram.

In the final step, the outranking relations is exploited to compare the alternatives by the elements of matrix $\tilde{Z}$. 
In this regard, graph $G=(V, J)$ is defined, where $V$ is the set of nodes and $J$ is the set of arcs. One node is considered for each alternative and an arc between two nodes of alternatives $a_{f}$ and $a_{g}$. Here, we propose fuzzy Kernel diagram. This diagram could depict uncertainty in comparison of alternatives. We draw solid arc if $a_{g}$ absolutely outranks $a_{f}$, that means $a_{g}$ is absolutely preferred to $a_{f}$ as shown in Fig. $6 a$. We proposed to draw long dashed arc if $a_{g}$ strongly outranks $a_{f}$ as shown in Fig. $6 b$, and dashed arc if $a_{g}$ weakly outranks $a_{f}$ as shown in Fig. $6 c$. If $a_{g}$ and $a_{f}$ are incomparable, we consider no arc between them as shown in Fig. $6 d$. In addition, Fig. $6 e$ illustrates the indifference between $a_{g}$ and $a_{f}$.

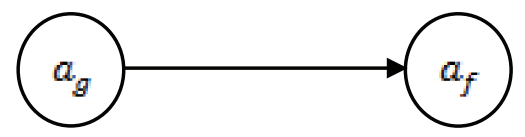

(a) Absolute preference

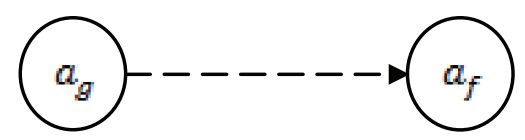

(b) Strong preference

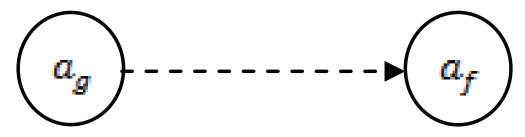

(c) Weak preference
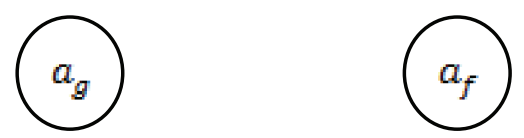

(d) Incomparability

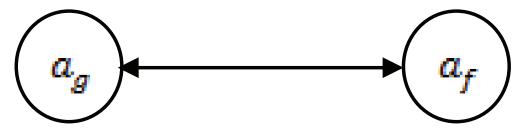

(e) Indifference

Fig. 6. Outranking relations represented by fuzzy Kernel diagram.

In order to determine the arcs, the elements of fuzzy global matrix $\tilde{Z}$ should be defuzzified. In this step, center of gravity defuzzification method is applied and $z_{g f}$ represents the defuzzified values. The intervals of the defuzzified values are defined for associated binary preferences are presented below:

$$
\left\{\begin{array}{cc}
\text { Incomparable } & 0 \leq z_{\text {gf }} \leq 0.25 \\
\text { Weak Preference } & 0.25<z_{\text {gf }} \leq 0.5 \\
\text { Strong Preference } & 0.5<z_{\text {gf }} \leq 0.75 \\
\text { Absolute Preference } & 0.75<z_{\text {gf }} \leq 1
\end{array}\right.
$$

In summary, you can find the associated steps of our combined method as follows:

\section{First phase: HFLTS operations}

Step 1. Determine the semantics and syntax of linguistic terms set and context-free grammar $G_{H}$.

Step 2. Gather the assessments of performance and criteria.

Step 3. Transform the assessments into HFLTS by transformation function $E_{G_{H}}$.

Step 4 : Obtain aggregate set for each assessment.

Step 5. Obtain fuzzy envelope for each assessment.

\section{Second phase: ELECTRE I outranking method}

Step 6. Rank alternatives for each criterion.

Step 7. Calculate fuzzy concordance and discordance indices.

Step 8. Compare alternatives by fuzzy Kernel diagram.

\section{An Illustrative Example}

In this part, a simple MCDA problem is added to provide a step by step solution in order to illustrate the proposed method. The problem is the selection of best supplier among three alternatives by considering three attributes including price, quality, and delivery. The best way of illustrating the relations between the criteria and alternatives is to use a hierarchy often applied in Analytic Hierarchy Process (AHP) [63]. The hierarchy of decision making is provided below:

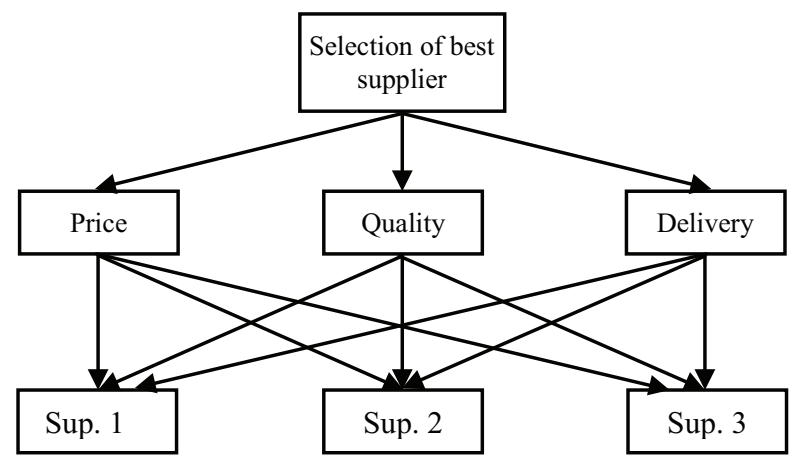

Fig. 7. The hierarchy of MCDA supplier selection problem. 
The steps of the method are presented below:

Step 1. At first, the semantic and syntax of linguistic term set $S$ and context-free grammar $G_{H}$ should be defined. We determine the linguistic term set $S$ as:

$$
S=\left\{\begin{array}{c}
\text { no importance }(\text { ni), very low importance }(v l i), \\
\text { low importance }(\text { li }), \text { medium } \\
\text { importance }(\text { mi }) \text {, high importance }(\text { hi }), \\
\text { very high importance }(\text { vhi }), \\
\text { absolute importance }(a i)
\end{array}\right\}
$$

Step 2. In this step, the importance of criteria is assessed with respect to the goal as Table 1. This will obtain the weights of criteria in next steps. Then, the performance of alternatives with respect to each criterion will be evaluated as you see in Tables 2,3 , and 4.

Table 1

The linguistic assessment of criteria with respect to the goal.

\begin{tabular}{cccc}
\hline & Price & Quality & Delivery \\
\hline Price & - & At most li & At most mi \\
Quality & At least hi & - & At least hi \\
Delivery & At least mi & At most li & - \\
\hline
\end{tabular}

Table 2

The linguistic assessment of alternatives with respect to price.

\begin{tabular}{lccc} 
& Supplier 1 & Supplier 2 & Supplier 3 \\
\hline Supplier 1 & - & At most vli & At most li \\
Supplier 2 & At least vhi & - & At least hi \\
Supplier 3 & At least hi & At most li & - \\
\hline
\end{tabular}

Table 3

The linguistic assessment of alternatives with respect to quality

\begin{tabular}{cccc}
\hline & $\begin{array}{c}\text { Supplier } \\
1\end{array}$ & Supplier 2 & Supplier 3 \\
\hline Supplier 1 & - & At most li & At most li \\
Supplier 2 & $\begin{array}{c}\text { At least } \\
\text { hi }\end{array}$ & - & $\begin{array}{c}\text { Between li and } \\
\text { mi }\end{array}$ \\
Supplier 3 & $\begin{array}{c}\text { At least } \\
\text { hi }\end{array}$ & $\begin{array}{c}\text { Between mi and } \\
\text { hi }\end{array}$ & - \\
\hline
\end{tabular}

Table 4

The linguistic assessment of alternatives with respect to delivery.

\begin{tabular}{lccc}
\hline & Supplier 1 & Supplier 2 & Supplier 3 \\
\hline Supplier 1 & - & At most li & At most mi \\
Supplier 2 & At least hi & - & At least hi \\
Supplier 3 & At least mi & At most li & - \\
\hline
\end{tabular}

Steps 3, 4, and 5. Firstly, each of comparative linguistic expressions is transformed into corresponding HFLTS. Then, the aggregate set is formed for each assessment. This aggregate set lets us to obtain fuzzy envelopes. For more details, follow the provided example below:

$E_{G_{H}}($ at most $l i)=\{n i, v l i, l i\}$

By using Eq. (17), simplified aggregate set is obtained:

$A_{a t \text { most } l i}=\left\{a_{L}^{n i}, a_{M}^{n i}, a_{M}^{\eta l i}, a_{M}^{l i}, a_{R}^{l i}\right\}$

We form fuzzy envelope similar to the presented fuzzy partitioning in Fig. 5.

$$
\begin{aligned}
& a=\min A_{a t} \operatorname{mast} l i \\
& =\min \left\{a_{L}^{n i}, a_{M}^{n i}, a_{M}^{v l i}, a_{M}^{l i}, a_{R}^{l i}\right\}=a_{L}^{n i}=0, \\
& d=\max A_{a t} \operatorname{most} l i \\
& =\max \left\{a_{L}^{n i}, a_{M}^{n i}, a_{M}^{v l i}, a_{M}^{l i}, a_{R}^{l i}\right\}=a_{R}^{l i}=0.5, \\
& b=o W A_{W^{1}}\left(a_{L}^{n i}, a_{M}^{n i}, a_{M}^{v l i}, a_{M}^{l i}, a_{R}^{l i}\right), \\
& c=o W A_{W^{1}}\left(a_{L}^{n i}, a_{M}^{n i}, a_{M}^{v l i}, a_{M}^{l i}, a_{R}^{l i}\right) . \\
& n=i+1=2+1=3, \\
& a=i / g=\frac{2}{6}=\frac{1}{3} \\
& W^{1}=\left(w_{1}^{2}, w_{2}^{2}, \ldots, w_{n}^{2}\right)^{T} \\
& \text { where } \\
& w_{1}^{1}=1 / 3, w_{2}^{1}=1 / 3(1-1 / 3), w_{3}^{1}=(1-1 / 3)^{2}, \\
& W^{1}=\left(\frac{1}{3}, \frac{2}{9}, \frac{4}{9}\right)^{T}, c=w_{1}^{1}, a_{M}^{l i}, w_{2}^{1}, a_{M}^{v l i}, w_{i}^{1}, a_{M}^{n i}, \\
& c=\frac{1}{3} \cdot a_{M}^{l i}+\frac{2}{9} \cdot a_{M}^{v l i}+\frac{4}{9} \cdot a_{M}^{n i} \\
& =\frac{1}{3} \cdot 0.33+\frac{2}{9} \cdot 0.17+\frac{4}{9} \cdot 0=0.15 \\
& b=a_{M}^{n i}=0 \\
& T_{a t} \operatorname{mast} l i=(0,0,0.15,0.5)
\end{aligned}
$$




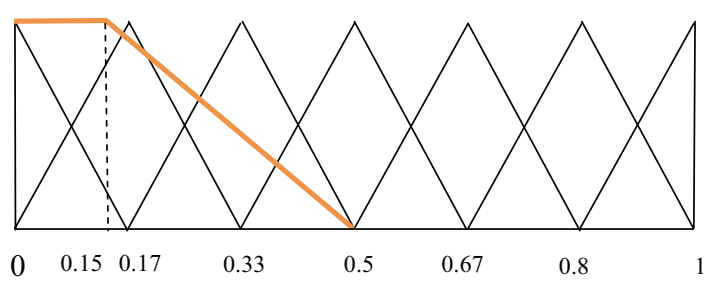

Fig. 8. $T_{\text {at most li }}$

Eventually, a trapezoidal fuzzy number will be obtained for each of evaluations as shown in Tables 5 , 6,7 , and 8 .

Table 5

The numerical assessments of the criteria with respect to the goal.

\begin{tabular}{cccc}
\multicolumn{4}{c}{ goal. } \\
\hline & Price & Quality & Delivery \\
\hline Price & - & $(0,0,0.15,0.5)$ & $(0,0,0.35,0.67)$ \\
& & - & $(0.5,0.85,1,1)$ \\
Quality & $(0.5,0.85,1,1)$ & - & - \\
& & & - \\
Delivery & $(0.33,0.65,1,1)$ & $(0,0,0.15,0.5)$ & \\
\hline
\end{tabular}

As mentioned before, the weights of criteria should be calculated using assessment of criteria with respect to goal as shown in Table 5. Similarly, the average performance of three suppliers is obtained by calculating the average amount of each row in Tables 6 , 7 , and 8 . Thus, the utility matrix, which represents the average performance ratings, and the weights of criteria are shown in Table 9. The weighted utility matrix is given in Table10.

Table 6

The numerical assessments of the alternatives with respect to price.

\begin{tabular}{cccc}
\hline & Supplier 1 & Supplier 2 & Supplier 3 \\
\hline Supplier 1 & - & $(0,0,0.028$, & $(0,0,0.15$, \\
& $0.33)$ & $0.5)$ \\
Supplier 2 & $(0.67,0.972,1$, & - & $(0.5,0.85,1$, \\
& $1)$ & & $1)$ \\
Supplier 3 & $(0.5,0.85,1,1)$ & $(0,0,0.15,0.5)$ & - \\
\hline
\end{tabular}

Table 7

The numerical assessments of the alternatives with respect to quality.

\begin{tabular}{cccc}
\hline & Supplier 1 & Supplier 2 & Supplier 3 \\
\hline Supplier 1 & - & $(0,0,0.15,0.5)$ & $(0,0,0.35,0.67)$ \\
& & & $(0.17,0.33,0.5$, \\
Supplier 2 & $(0.5,0.85,1$, & - & $0.67)$ \\
& $1)$ & & - \\
Supplier 3 & $(0.5,0.85,1$, & $(0.33,0.5,0.67$, & \\
& $1)$ & $0.83)$ & \\
\hline
\end{tabular}

Table 8

The numerical assessments of the alternatives with respect to delivery.

\begin{tabular}{cccc}
\hline & Supplier 1 & Supplier 2 & Supplier 3 \\
\hline Supplier 1 & - & $(0,0,0.15,0.5)$ & $(0,0,0.35,0.67)$ \\
Supplier 2 & $(0.5,0.85,1,1)$ & - & $(0.5,0.85,1,1)$ \\
Supplier 3 & $(0.33,0.65,1,1)$ & $(0,0,0.15,0.5)$ & - \\
\hline
\end{tabular}

Table 9

The utility matrix (average performance ratings) and criteria weights.

\begin{tabular}{cccc}
\hline \multirow{4}{*}{ Price } & Quality & Delivery \\
\hline \multirow{2}{*}{ Weights } & $\begin{array}{c}0,0,0.25, \\
0.585)\end{array}$ & $\begin{array}{c}(0.5,0.85,1, \\
1)\end{array}$ & $\begin{array}{c}(0.165,0.325, \\
0.575,0.75)\end{array}$ \\
& $(0,0,0.89$, & $(0,0,0.15$, & $(0,0,0.25$, \\
Supplier 1 & $0.415)$ & $0.5)$ & $0.585)$ \\
& & $0.335,0.59$, & $(0.5,0.85,1$, \\
Supplier 2 & $(0.585,0.911$, & $(0.75,0.835)$ & $1)$ \\
& $1,1)$ & $0.415,0.675,0$ & $(0.165,0.325,0$ \\
Supplier 3 & $(0.25,0.425$, & $(0.455,0.75)$ \\
& $0.575,0.75)$ & $.835,0.915)$ & .575, \\
\hline
\end{tabular}

Table 10

The weighted utility matrix.

\begin{tabular}{cccc}
\hline & Price & Quality & Delivery \\
\hline \multirow{2}{*}{ Supplier 1 } & $(0,0,0.222$, & $(0,0,0.15$, & $(0,0,0.143$, \\
& $0.242)$ & $0.5)$ & $0.438)$ \\
Supplier 2 & $(0,0,0.25$, & $(0.167,0.501,0$ & $(0.082,0.276,0$ \\
& $0.585)$ & $.75,0.835)$ & $.575,0.75)$ \\
Supplier 3 & $(0,0,0.143$, & $(0.207,0.573$, & $(0.027,0.105,0$ \\
& $0.438)$ & $0.835,0.915)$ & $.330,0.562)$ \\
\hline
\end{tabular}

Step 6. In this step, the alternatives are ranked with respect to each criterion as presented in Tables 11, 12, and 13 . We apply center of gravity defuzzification 
method to rank the fuzzy numbers. Considered fuzzy numbers are average amount of row elements of performance ratings shown in Tables. 6, 7, and 8. This ranking will help us to obtain fuzzy concordance and discordance indices in next step. For instance, center of gravity defuzzifies $(0,0,0.089,0.415)$ as follows:

$$
\frac{\int_{0}^{\text {u.usy }} x d x+\int_{0.089}^{0.415}\left(-3.07 x^{2}+1.27 x\right) d x}{\int_{0}^{0.089} d x+\int_{0.089}^{0.415}(-3.07 x+1.27) d x}=0.143
$$

Table 11

Ranking of alternatives with respect to price.

\begin{tabular}{ccc}
\hline & Average & Defuzzified Value \\
\hline Supplier 1 & $(0,0,0.089,0.415)$ & 0.143 \\
Supplier 2 & $(0.585,0.911,1,1)$ & 0.855 \\
Supplier 3 & $(0.25,0.425,0.575,0.75)$ & 0.488 \\
\hline Ranking & Supplier 2 >-Supplier 3 > Supplier 1 \\
\hline
\end{tabular}

Table 12

Ranking of alternatives with respect to quality.

\begin{tabular}{lcc}
\hline & Average & Defuzzified Value \\
\hline Supplier 1 & $(0,0,0.15,0.5)$ & 0.178 \\
Supplier 2 & $(0.335,0.59,0.75,0.835)$ & 0.597 \\
Supplier 3 & $(0.415,0.675,0.835,0.915)$ & 0.700 \\
\hline Ranking & Supplier 3 >-Supplier 2 > Supplier 1 \\
\hline
\end{tabular}

Table 13

Ranking of alternatives with respect to delivery.

\begin{tabular}{lcc}
\hline & Average & Defuzzified Value \\
\hline Supplier 1 & $(0,0,0.25,0.585)$ & 0.220 \\
Supplier 2 & $(0.5,0.85,1,1)$ & 0.820 \\
Supplier 3 & $(0.165,0.325,0.575,0.75)$ & 0.480 \\
\hline Ranking & Supplier 2 > Supplier 3 > Supplier 1 \\
\hline
\end{tabular}

Step 7. In this step, fuzzy concordance and discordance indices are computed to construct fuzzy concordance and discordance matrices. By taking into account the ranking of alternatives, the fuzzy concordance indices are obtained through adding criteria weights each of which the alternative ranking is higher. Then, it will be divided by the total amount of criteria weights. Fuzzy concordance table is presented in Table 14:

Table 14

Fuzzy concordance table.

\begin{tabular}{|c|c|c|c|}
\hline & Supplier 1 & Supplier 2 & Supplier 3 \\
\hline $\begin{array}{c}\text { Supplier } \\
1\end{array}$ & - & $\frac{(0,0,0,0)}{\widetilde{w}_{c o m b}+\tilde{w}_{\text {acch }}+\tilde{w}_{d s s}}$ & $\frac{(0,0,0,0)}{\widetilde{w}_{c o m}+\widetilde{w}_{a c c l .}+\widetilde{w}_{d e s}}$ \\
\hline $\begin{array}{l}\text { Supplier } \\
\quad 2\end{array}$ & $\frac{\tilde{w}_{c o m}+\tilde{w}_{a c c h}+\tilde{w}_{d s s}}{\tilde{w}_{c o m}+\tilde{w}_{a c c h}+\tilde{w}_{d s s}}$ & - & $\frac{\tilde{w}_{c o m}+\tilde{w}_{d s s}}{\tilde{w}_{\text {com }}+\tilde{w}_{\text {acch }}+\tilde{w}_{d s s}}$ \\
\hline $\begin{array}{c}\text { Supplier } \\
3\end{array}$ & $\frac{\tilde{w}_{c o m}+\tilde{w}_{a c c h}+\tilde{w}_{d s s}}{\tilde{w}_{c o m n}+\tilde{w}_{\text {acch }}+\tilde{w}_{d s s}}$ & $\frac{\tilde{w}_{a c c h}}{\tilde{w}_{c o m L}+\widetilde{w}_{a c c l}+\widetilde{w}_{d g s}}$ & - \\
\hline
\end{tabular}

From Table 14, we have

$$
C=\left\lfloor\begin{array}{ccc}
- & (0,0,0,0) & (0,0,0,0) \\
(1,1,1,1) & - & (0.25,0.27,0.45,0.57) \\
(1,1,1,1) & (0.43,0.55,0.73,0.75) & -
\end{array}\right\rfloor
$$

Based on the Eq. (22), the discordance matrix is obtained using Table 10 as follows:

$$
D=\left[\begin{array}{ccc}
- & 1 & 1 \\
0 & - & 0.231 \\
0 & 0.768 & -
\end{array}\right]
$$

Based on Eq. (24), the supplement of discordance matrix will be as follows:

$$
D^{\prime}=\left[\begin{array}{ccc}
- & 0 & 0 \\
1 & - & 0.769 \\
1 & 0.232 & -
\end{array}\right]
$$

Finally, the fuzzy global matrix $\tilde{Z}$ is built through multiplication of matrices $\tilde{C}$ and $D^{\prime}$ as follows:

$$
z=\left[\begin{array}{ccc}
- & (0,0,0,0) & (0,0,0,0) \\
(1,1,1,1) & - & (0,192,0,207,0.346,0,438) \\
(1,1,1,1) & (0.099,0.127,0.169,0.174) & -
\end{array}\right]
$$

After defuzzification, the preferences of the alternatives will be obtained by using Eq. (25). Therefore, supplier 2 is absolutely preferred to supplier 1 , supplier 3 is absolutely preferred to supplier 1 , and supplier 2 is weakly preferred to supplier 3 . Supplier 3 is also incomparable to supplier 2.

Step 8. Consequently, the fuzzy Kernel graph is drawn based on the $\tilde{Z}$ matrix as Fig. 8. According to Fig. 6, solid arc is drawn from suppliers 2 and 3 to 
supplier 1 to represent absolutely preferred nodes, and dashed line from supplier 2 to supplier 3. Eventually, the fuzzy Kernel graph in Fig. 9 depicts that supplier 2 outranks other two suppliers using HFLTS-ELECTRE I method.

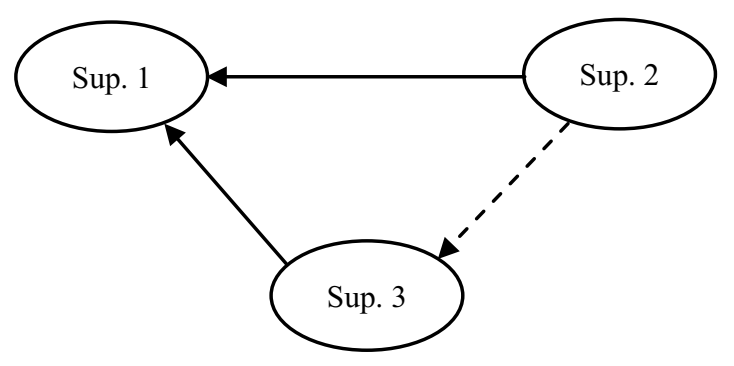

Fig. 9. Fuzzy Kernel graph

\section{Conclusion}

In this study, ELECTRE I outranking method using hesitant fuzzy linguistic term set is proposed. Since decision making involves uncertainty and imprecision, DMs prefer to render linguistic judgments about decision alternatives and criteria. Our proposed method facilitates decision making process due to using comparative linguistic expressions to evaluate the alternatives and criteria and it could be a DM-friendly MCDA method. Fuzzy sets theory and subsequent developments empowers us to numerically interpret the uncertainty of MCDA problems. Ultimately, ELECTRE I method is established to investigate binary relations of alternatives and criteria in order to compare them by comparative linguistic terms.

In this proposed HFLTS-ELECTRE I method, the combination matrix of concordance and discordance remains fuzzy. Our method offers an evolution in outranking relations through elimination of concordance and discordance thresholds form ELECTRE I method. Hence, we propose fuzzy Kernel diagram to represent the preferences of actions. This new diagram uses dashed lines to depict decision maker's uncertainty toward actions. Since fuzzy Kernel diagram is implemented, defuzzification of the fuzzy concordance matrix is not needed and we continue the calculations by fuzzy values until the final step. Thus, the output clearly illustrates decision maker's assessments and his/her preferences. Future works could focus on extensions of HFLTS for other members of ELECTRE family or outranking methods. In addition, extension of fuzzy Kernel diagram could represent decision maker's preferences in detail.

\section{References}

[1] I. N. Durbach and T. Stewart, Using expected values to simplify decision making under uncertainty, Omega, vol. $37, n^{\circ} 2$, p. 312-330, 2009.

[2] X. Wang and E. Triantaphyllou, Ranking irregularities when evaluating alter- natives by using some ELECTRE methods, Omega, vol. 36, p. 45-63, 2008.

[3] R. T. Clemen, Making hard decisions: an introduction to decision analysis, 2nd ed., Belmont: Duxbury Press at Wadsworth Publishing Company, 1996.

[4] A. Hatami-Marbini and M. Tavana, An extension of the Electre I method for group decision-making under a fuzzy environment, Omega, vol. 39 , p. 373-386, 2011.

[5] J. Figueira, S. Greco and M. Ehrgott, Multiple criteria decision analysis: state of the art surveys, New York: Springer, 2005.

[6] T. J. Stewart and F. B. Losa, Towards reconciling outranking and value measurement practice, European Journal of Operational Research, vol. 145, no 3, p. 645659, 2002.

[7] C. Zopounidis and M. Doumpos, Multicriteria classification and sorting methods: a literature review, European Journal of Operational Research, vol. 138, $\mathrm{n}^{\circ}$ 2, p. 229-246, 2002.

[8] B. Roy and D. Vanderpooten, An overview on The European School of MCDA: emergence, basic features and current work, European Journal of Operational Research, vol. 99, n 1, pp. 26-27, 1997.

[9] M. Doumpos, Y. Marinakisa, M. Marinakia and C. Zopounidis, An evolutionary approach to construction of outranking models for multicriteria classifica- tion: the case of the ELECTRE TRI method, European Journal of Operational Research, vol. 199, n² 2, p. 496-505, 2009.

[10] F. J. Andre, I. Herrero and L. Riesgo, Amodified DEA model to estimate the importance of objectives with an application to agricultural economics, Omega, vol. $38, \mathrm{n}^{\circ}$ 5, p. 371-382, 2010.

[11] M. A. Hinojosa and A. M. Marmol, Axial solutions for multiple objective linear problems: an application to target setting in DEA models with preferences, Omega, vol. 39, nº 2, p. 159-167, 2011.

[12] R. E. Steuer, J. Silverman and A. J. Whisman, A combined Tchebycheff/aspiration criterion vector interactive multi objective programming procedure, Management Science, vol. 39, $\mathrm{n}^{\circ}$ 10, p. 1255-1260, 1993.

[13] B. Roy, The outranking approach and the foundations of ELECTRE methods, Theory and Decision, vol. $31, \mathrm{n}^{\circ} 1$, p. 49-73, 1991. 
[14] J. Paelinck, Qualiflex: a flexible multiple-criteria method, Economic letters, vol. 1, no 3, p. 193-197, 1978.

[15] M. Roubens, Preference relations on actions and criteria in multi-criteria decision making, European Journal of Operational Research, vol. 10, n 1, p. 51-55, 1982.

[16] H. Pastijn and J. Leysen, Constructing an outranking relation with oreste, Mathematical and Computer Modelling, vol. 12, nº 10-11, p. 1255-1268, 1989.

[17] J. P. Leclercq, Propositions d'extension de la notion de dominance en presence de relations d'ordre sur les pseudo-criteres: MELCHIOR, Revue Belge de Recherche Operationelle de Statistique et d'hformatique, vol. 24, $\mathrm{n}^{\circ}$ 1, p. 32-46, 1984.

[18] B. Matarazzo, Multicriterion analysis of preferences by means of pairwise actions and criterion comparisons (MAPPAC), Applied Mathematics and Computation, vol. 18, no 2, p. 119-141, 1986.

[19] J. C. Vansnick, On the problem of weights in multiple criteria decision making: the non-compensatory approach, European Journal of Operational Research, vol. 24, p. 288-294, 1986.

[20] R. Benayoun, B. Roy and B. Sussman, ELECTRE: Une méthode pour guider le choix en présence de points de vue multiples, Note de travail 49, SEMA-METRA international, direction scientifique, Paris, 1966.

[21] B. Roy, Classement et choix en presence de points de vue multiples (la methode ELECTRE), Revue Francaise d'Informatique et de Recherche Operationnelle, vol. 8, p. 57-75, 1968.

[22] B. Roy and P. Bertier, La Methode ELECTRE II: Use Methode de Classement en Presence de Criteres Multiples., Note de Travail No. 142, Direction Scientifique, Group Metra, Paris, 1971.

[23] B. Roy and P. Bertier, La methode ELECTRE II: Une application au mediaplanning, de $O R$ 72, M. Ross, Ed., Amsterdam, North Holland, 1973, pp. 291-302.

[24] B. Roy, Electre III Un algorithme de classements fonde sur une representation floue en presence de criteres multiples, Cahairs du CERO, vol. 20, $\mathrm{n}^{\circ}$ 1, p. 3-24, 1978.

[25] M. Rogers and M. Bruen, A new system for weighting environmental criteria for use within ELECTRE III, European Journal of Operational Research, vol. 107, $\mathrm{n}^{\circ}$ 3, p. 552-563, 1998.

[26] B. Roy and J. C. Hugonnard, Ranking of suburban line extension alternatives on the Paris metro system by a multicriteria method, Transportation Research, vol. 16A, no 4, p. 301-312, 1982.

[27] B. Roy and J. C. Hugonnard, Classement des prolongements de lignes de metro en banlieue parisienne (presentation d'une methode multicritere originale), Cahiers du CERO, vol. 24, nº 2,3,4, p. 153-171, 1982.

[28] W. Yu, ELECTRE TRI: Aspects methodologiques et manuel d'utilisation, Document du LAMSADE 74,
Universite Paris-Dauphine, 1992.

[29] S. Greco, M. Kadzinski, V. Mousseau and R. Słowinski, ELECTREGKMS: robust ordinal regression for outranking methods, European Journal of Operational Research, vol. 214, $\mathrm{n}^{\mathrm{o}}$ 1, p. 118-135, 2011.

[30] J. P. Brans and P. Vincke, A preference ranking organization method: the PROMETHEE method for MCDM, Management Science, vol. 31, no 6, p. 647-656, 1985.

[31] M. Behzadian, R. B. Kazemzadeh, A. Albadvi and M. Aghdas, PROMETHEE: A comprehensive literature review on methodologies and applications, European Journal of Operational Research, vol. 200, nº 1, pp. 198215, 2010.

[32] B. Roy and D. Bouyssou, Aide Multicritere a la Decision: Methodes et Cas, Paris: Economica, 1993.

[33] B. Roy, Partial preference analysis and decision-aid: the fuzzy outranking relation concept, de Conflicting objectives and decisions, New York, Wiley, 1977, pp. 4075 .

[34] J. L. Siskos, J. Lochard and J. Lombardo, A multicriteria decision-making methodology under fuzziness: application to the evaluation of radiological protection in nuclear power plants, TIMS Studies in the Management Sciences, vol. 20, p. 261-283, 1984.

[35] M. Sevkli, An application of the fuzzy ELECTRE method for supplier selection, International Journal of Production Research, vol. 48, $\mathrm{n}^{\mathrm{o}} 12$, pp. 3393-3405, 2010.

[36] T. Ertay and C. Kahraman, Evaluation of design requirements using fuzzy outranking methods, International Journal of Intelligent Systems, vol. 22, p. 1229-1250, 2007.

[37] B. Vahdani, A. Jabbari, V. Roshanaei and M. Zandieh, Extension of the ELECTRE method for decision-making problems with interval weights and data, International Journal of Advanced Manufacturing Technology, vol. 50 , no 5-8, p. 793-800, 2010.

[38] B. Vahdani and H. Hadipour, Extension of the ELECTRE method based on interval-valued fuzzy sets, Soft Computing, vol. 15, p. 569-579, 2011.

[39] T. Chen, An ELECTRE-based outranking method for multiple criteria group decision making using interval type-2 fuzzy sets, Information Sciences, vol. 263 , p. 121, 2014.

[40] K. Devi and P. Yadav S., A multicriteria intuitionistic fuzzy group decision making for plant location selection with ELECTRE method, The International Journal of Advanced Manufacturing Technology, vol. 66, p. 12191229, 2013.

[41] B. Vahdani, S. M. Mousavi, R. Tavakkoli-Moghaddam and H. Hashemi, A new design of the elimination and choice translating reality method for multi-criteria group 
decision-making in an intuitionistic fuzzy environment, Applied Mathematical Modelling, vol. 37, $\mathrm{n}^{\circ}$ 4, pp. 17811799, 2013.

[42] J. Li, M. Lin and J. Chen, ELECTRE Method Based on Interval-valued Intuitionistic Fuzzy Number, Applied Mechanics and Materials, Vols. \%1 de \%2220-223, pp. 2308-2312, 2012.

[43] M. C. Wue and T. Y. Chen, The ELECTRE multicriteria analysis approach based on Atanassov's intuitionistic fuzzy sets, Expert Systems with Applications, vol. 38, p. 12318-12327, 2011.

[44] V. Torra, Hesitant fuzzy sets, International Journal of Intelligent Systems, vol. 25, nº 6, p. 529-539, 2010.

[45] R. M. Rodríguez, L. Martínez, V. Torra, Z. S. Xu and F. Herrera, Hesitant fuzzy sets: state of the art and future directions, International Journal of Intelligent Systems, vol. 29, nº 6, p. 495-524, 2014.

[46] L. Zadeh, Fuzzy logic = computing with words, IEEE Transactions on Fuzzy Systems, vol. 4, $\mathrm{n}^{\circ} 2$, pp. 103-111, 1996.

[47] F. Herrera, S. Alonso, F. Chiclana and E. HerreraViedma, Computing with words in decision making: foundations, trends and prospects, Fuzzy Optimization and Decision Making, vol. 8, nº 4, p. 337-364, 2009.

[48] L. Martínez, D. Ruan and F. Herrera, Computing with words in decision support systems: an overview on models and applications, International Journal of Computational Intelligence Systems, vol. $3, \mathrm{n}^{\circ} 4$, p. 382395, 2010.

[49] R. M. Rodriguez, L. Martinez and F. Herrera, Hesitant fuzzy linguistic term sets for decision making, IEEE Transactions on Fuzzy Systems, vol. 20, n ${ }^{\mathrm{o}}$ 1, pp. 109119, 2012.

[50] H. Liu and R. M. Rodriguez, A fuzzy envelope for hesitant fuzzy linguistic term set and its application to multicriteria decision making, Information Sciences, vol. 258, p. 220-238, 2014.

[51] L. Zadeh, The concept of a linguistic variable and its applications to approximate reasoning, Information Sciences, 8, 9, pp. 199-249 (I). 301-357 (II), 43-80 (III), 1975.

[52] C. T. Chen, Extensions of the TOPSIS for group decision-making under fuzzy environment, Fuzzy Sets and Systems, vol. 114, $\mathrm{n}^{\mathrm{o}}$ 1, p. 1-9, 2000.

[53] S. H. Tsaur, T. Y. Chang and C. H. Yen, The evaluation of airline service quality by fuzzy MCDM, Tourism Management, vol. 23 , p. 107-115, 2002.

[54] L. Zadeh, Fuzzy sets, Information and Control, vol. 8, $\mathrm{n}^{\mathrm{o}}$ 3, p. 338-353, 1965.

[55] R. M. B. B. Rodríguez, H. Bustince, Y. C. Dong, B. Farhadinia, C. Kahraman, L. Martínez, V. Torra, Y. J. $\mathrm{Xu}, \mathrm{Z}$. S. $\mathrm{Xu}$ and H. F, A Position and Perspective Analysis of Hesitant Fuzzy Sets on Information Fusion in
Decision Making. Towards High Quality Progress, Information Fusion, vol. 29, pp. 89-97, 2016.

[56] D. Filev and R. Yager, On the issue of obtaining OWA operator weights, Fuzzy Sets and Systems, vol. 94, p. 157-169, 1998.

[57] H. J. Zimmermann, Fuzzy set theory and its applications, 2nd, Ed., Boston: Kluwer Academic Publishers, 1991.

[58] D. J. Dubois, Fuzzy sets and systems: theory and applications, New York: Academic Press, 1980.

[59] G. J. Klir and B. Yuan, Fuzzy sets and fuzzy logic: theory and applications, New York: Prentice-Hall, 1995.

[60] K. P. Yoon and C. L. Hwang, Multiple Attribute Decision Making, An Introduction. Sage University Paper series on Quantitative Applications in the Social Sciences, Sage, Thousand Oaks, 1995.

[61] S. J. Chen and C. L. Hwang, Fuzzy Multiple Attribute Decision Making, Methods and Applications, Lecture Notes in Economics and Mathematical Systems, vol. 375, Heidelberg: Springer, 1992.

[62] T. Aouam, S. I. Chang and E. S. Lee, Fuzzy MADM: An outranking method, European Journal of Operational Research, vol. 145 , p. 317-328, 2003.

[63] T. L. Saaty, The Analytic Hierarchy Process, New York: McGraw Hill, 1980. 